\title{
Examining the Role of Friendship in Mentoring Relationships between Graduate Students and Faculty Advisors
}

COLLECTED ESSA ON LEARNIN

\author{
Jacqueline L. Beres, Brock University
}

Jess C. Dixon, University of Windsor

Although previous studies have offered empirical and anecdotal support for academic mentoring, there are still considerable gaps in understanding the specific actions or components that are present in these relationships. Research has shown that academic faculty mentors provide all of Kram's (1988) mentoring functions to their graduate student protégés. Despite numerous claims to the presence of "friendship" in graduate student-faculty advisor mentoring relationships, others question if friendship is even possible within this context. Thus, there is ambiguity about the role of this particular function in academic mentoring. In our attempt to reconcile results from a previous study on graduate student-faculty advisor mentoring and better understand the potential role and temporal development of friendship within this domain, we sought clarification in the existing literature. To our surprise, the literature lacks consensus on the topic and requires additional scholarly attention. Consequently, the purpose of this paper is to share insights from our previous study examining mentoring in academia, summarize empirical findings and conceptual advancements on the topic of friendship in graduate student-faculty advisor mentoring relationships, and propose directions for further inquiry in this area, in the hope of strengthening academic mentoring relationships.

\section{Introduction}

I

t's nice to have such a great friend. Somebody I can turn to, somebody I respect and I trust, and I know will always be there for me.

Graduate student protégé

Having doctoral students has enriched my personal life; you know, I'm friends with many of them.

-Faculty mentor

Mentoring relationships typically exist between experienced individuals (mentors) and their less experienced counterparts (protégés). Through their interactions, mentors provide protégés with disciplinary and career guidance, and also assist with personal development. Within academia, graduate students and faculty members in mentoring relationships often experience positive outcomes. For example, in their longitudinal study, Paglis, Green, and Bauer (2006) determined that faculty advisors had a positive impact on their students' research productivity and research self-efficacy. Others have found that protégés report greater publications and higher levels of satisfaction when compared with their non-mentored peers (Cronan-Hillix, Gensheimer, Cronan-Hillix, \& Davidson, 1986). Similarly, faculty advisors who serve as mentors to their students are viewed as capable of fostering talent and may develop 
increased publication records because of their collaborative work with students (Kanter, 1977). Given the many benefits of these relationships, mentoring in higher education is an important topic worthy of investigation.

Despite empirical evidence and anecdotal support for mentoring (e.g., Allen, Eby, Poteet, Lentz, \& Lima, 2004; De Four-Babb, Pegg, \& Beck, 2015; Eby, Allen, Evans, Ng, \& DuBois, 2008), there are still considerable gaps in understanding the specific actions or components that are present in various mentoring relationships. The most frequently used conceptualization of mentoring functions is Kram's (1988) framework, which is comprised of nine functions divided into two primary groupings: career functions and psychosocial functions. Research has shown that, collectively, academic faculty advisors provided all of Kram's (1988) mentoring functions to their graduate student protégés (e.g., Beres \& Dixon, 2014; Clark, Harden, \& Johnson, 2000). Despite numerous claims to the presence of "friendship" in these graduate student-faculty advisor mentoring relationships (Gardiner, 1998, 2008; Young, Alvermann, Kaste, Henderson, \& Many, 2004), others question if friendship is even possible within this context (Johnson, 2008). Thus, there is considerable ambiguity surrounding the role of this particular function in academic mentoring.

In our attempt to reconcile results from a previous study on graduate student-faculty advisor mentoring and better understand the potential role of friendship and its temporal development within this domain, we sought clarification in the existing literature. To our surprise, the literature lacks consensus on the topic and requires additional scholarly attention. For example, we found a limited number of studies that explicitly examined the role of friendship in academic mentoring relationships. Within studies that do explore friendship, some acknowledge its central importance (e.g., Young et al., 2004), yet others report that friendship is the least prevalent mentoring function (Clark et al., 2000). Conceptual advancements, such as those proposed by Gardiner (1998, 2008), draw much-needed attention to the issue of friendship in mentoring relationships, but fail to provide sufficiently delineated definitions or clear models. Possible role conflict or incompatibility when advisors and students develop friendship relationships has also been considered (e.g., Johnson, 2008; Johnson \& Huwe, 2003). Finally, because of the retrospective nature of most findings, for those who report having friendships, it is not possible to determine precisely when during the mentoring relationship that friendship developed. Given this confusion and lack of unified insight, the purpose of this article is threefold. First, we share insights from our previous study examining mentoring in academia. Second, we describe definitional issues that may prevent a clear understanding of the boundaries between friendship and related concepts, summarize empirical findings and conceptual advancements on the topic of friendship in graduate student-faculty advisor mentoring relationships, and provide a description of the possible role conflict and incompatibility when advisors and students develop friendships. Last, we propose directions for further inquiry in this area with the hope that previous, disparate findings could eventually be reconciled and academic mentoring relationships would be strengthened.

\section{Mentoring: A Brief Introduction}

The most widely cited aspect of mentoring research is Kram's (1988) conceptualization of mentoring functions (Allen et al., 2004), which refer to the specific actions that are provided in mentoring relationships. Kram classified these functions into two categories: career functions, which enhance a protégé's career development, and psychosocial functions, which help to build a protégé's competence and identity. Career functions are comprised of sponsorship, exposure and visibility, protection, coaching, and challenging assignments. Psychosocial functions include acceptance and confirmation, role modelling, counselling, and friendship. Although Kram's mentoring functions were developed in a business setting, they have been widely, and often uncritically, adopted in academia. This phenomenon is noteworthy, as some have suggested the crossover 
of mentoring concepts between disciplinary silos is rare (e.g., Bearman, Blake-Beard, Hunt, \& Crosby, 2010; Eby et al., 2008), and it is unclear whether adopting mentoring functions across various contexts is appropriate.

Mentoring in academia can take many forms, including peer mentoring among undergraduate or graduate students (e.g., Dorsey \& Baker, 2004), between more experienced and less experienced faculty members (e.g., Ciuffetelli Parker \& McQuirter Scott, 2010; Griffin \& Beatty, 2012) and most commonly, between graduate students and faculty members (e.g., Tenenbaum, Crosby, \& Gliner, 2001). The mentoring relationships that develop between graduate students and faculty members have been found to play a critical role in graduate students' success, and not having an advisor or experiencing mismatches in these critical relationships impacts doctoral student attrition (Golde, 2005; Lovitts, 2001). Moreover, given that roughly half of all doctoral students do not complete their degrees (Lovitts, 2001), graduate student-faculty advisor mentoring relationships warrant continued examination.

\section{Friendship in Graduate Student- Faculty Advisor Mentoring: A Case Study}

Using matched pairs of mentors and protégés, we previously sought to determine what mentoring functions select doctoral dissertation advisors provided for their doctoral students within the field of sport management (Beres \& Dixon, 2014). We used a descriptive case study approach (Yin, 2009), bounded by academic discipline (sport management), geographical region (North America), employment status (limited to those employed as faculty members in North American post-secondary institutions), and contact information (valid university contact information obtained through public records). A descriptive approach was appropriate as we sought an in-depth understanding of a phenomenon with critical contextual conditions (Yin, 2009).

Our use of purposive sampling is further aligned with a descriptive case study approach. We selected five faculty advisors (two males and three females) who demonstrated high levels of scholarly productivity, coupled with previous experience advising large numbers of doctoral students. Purposive sampling was appropriate as we felt these individuals represented unique cases and, given their previous experiences advising many students, could likely offer insight into mentoring relationships (Savin-Baden \& Major, 2013). We then used stratified random sampling to select one male and one female doctoral student for each advisor. Information pertaining to participants' ages, ethnicities, and class backgrounds was not collected, as we deemed that it was not pertinent to the research questions being examined in that study.

After receiving ethical clearance and testing our interview protocol via pilot interviews, we conducted one semi-structured telephone interview with each participant. Interviews were conducted at participants' convenience and ranged from 27 to 55 minutes in duration. As an example of sample interview questions, mentors were asked if they could "please describe how you helped your doctoral students' personal development," while protégés were asked if they could "please describe how your advisor helped your personal development." All interviews were digitally recorded and transcribed verbatim. Data analysis followed an iterative process that included both deductive and inductive approaches using open and axial coding (Strauss \& Corbin, 1998). Participants' responses were initially categorized deductively using Kram's (1988) framework, with these functions then adapted inductively to capture the nuances of academia. Although we found varying levels of support for all of Kram's career and psychosocial functions, the topic of friendship was identified repeatedly by participants in our study.

In an effort to avoid influencing participants' answers to fit Kram's (1988) mentoring functions, we refrained from specifically asking questions about the individual functions; that is, participants were not 
explicitly asked about friendship in their mentoring relationships. Instead, protégés were asked to describe the guidance, counselling, or advice they received from their mentors, along with the ways their mentors helped to advance their careers and personal development. Similarly, mentors were asked questions phrased to elicit descriptions of the actions they took on behalf of their protégés. For a more detailed description of the methods employed and the results found in this earlier study, please refer to Beres and Dixon (2014).

Of particular interest to the present article is that all of the mentors in our previous study noted that they were friends with at least some of their former doctoral students. Selected quotes substantiating this claim include "I've now become friends with some of my doctoral students" and "I would describe the relationships with most of my former doctoral students as very, very good; many of them I count as friends." One mentor added, "I've developed some wonderful friendships from former students" while another mentor echoed, "I'm friends with many of them; I remain friends with many of them." In addition to the mentors' specific acknowledgments of their friendships, two thirds of the protégés in our study explicitly used the word "friend" or some variation thereof when describing their relationships with their mentors. Protégés were very clear about their feelings, saying, "I consider her a friend," "it's nice to have such a great friend," "we've just developed a great friendship," and my mentor "also became a friend in the department." Another protégé added, "I think she called it a peer relationship, but I call it a friendship. She's one of my better friends."

Based on the evidence presented above, participants often used the term "friendship" to describe the close interpersonal relationships that they developed and maintained with their former faculty advisors. However, we must note that we did not provide participants with an operational definition of friendship. In some instances, mentors and protégés considered activities such as playing sports and enjoying dinners together, joined by their respective families, to be examples of friendship. In other instances, participants did not provide definitions of friendship, but simply referred to having a "friend," "friendships," "someone I think of often," and "somebody I can turn to, somebody I respect and I trust, and I know will always be there for me." The lack of an explicit definition means we were unsure of whether these descriptions were consistent with what has been reported in existing literature, or if true friendship is even possible within this context. It was at this point that we turned to the literature in hopes of reconciling our results. What we found, as shared in the following sections, was both inconsistent and perplexing.

\section{Exploring the Role of Friendship in the Mentoring Literature}

Friendship in mentoring relationships is a complex concept, and the literature exploring this domain is fraught with definitional inconsistencies. Like the topic of mentoring itself, the notion of friendship could mean different things to different people. Broadly, mentoring has been criticized for lacking a clear and consistent definition (e.g., Bozeman \& Feeney, 2007); these same criticisms can be applied to friendship within mentoring relationships. Although Wrightsman (1981) discusses mentoring in general, there is a parallel between his comment that "there is a false sense of consensus, because at a superficial level everyone 'knows' what mentoring is" (p. 3) and the specific role of friendship in mentoring relationships. We believe this implicit understanding of friendship may have contributed to an unnecessary complication in the literature. Having a clear(er) definition of what friendship entails within graduate student-faculty advisor mentoring relationships would allow researchers to better understand the role and extent of this particular mentoring function, with an aim to improve these critical relationships and their associated outcomes.

According to Kram (1988), the psychosocial function of friendship is "characterized by social interaction that results in mutual liking and understanding and enjoyable informal exchanges about work and outside work experiences" (p. 38). It 
also involves "sharing personal experiences" (p. 38) and allows protégés to develop peer-like relationships with more experienced individuals. Unfortunately, Kram does not provide additional parameters on what constitutes friendship interactions within mentoring relationships. It is certainly reasonable to expect that the specific actions and engagements within individual mentoring relationships would vary based on personal preferences and interests; however, the sweeping description that friendship in mentoring "combines elements of a teacher, a parent, and a good friend" (p. 38) does not offer any clarity. Although Kram suggests that there are limits to friendship in mentoring relationships, stating that many individuals restrict their social interactions to work contexts, she complicates matters by intertwining "increasing mutuality," "colleagueship," and "informality" (p. 38) in her discussion of friendship, without elaboration. While Kram's functions offer an important framework of the behaviours taking place within mentoring relationships, further clarification, especially in an academic context, is required.

While Kram (1988) has had an undeniable impact on the field of mentoring research, many others have also contributed informatively on the topic. When examining some of these authors' use of "friend," "friends," "friendship," and related terms (see Table 1), similar definitional challenges emerge. Clutterbuck (2001) and Gardiner (2008) both use a wide variety of terms to describe these relationships; regrettably, sufficient definitions are not provided in either publication, further muddying the concept.

\section{Empirical Findings}

The idea of friendship in academic mentoring relationships is not new, nor is the contested nature of this phenomenon. When asked to describe whether or not they socialized with their academic mentors, doctoral students in one study reported an even split; half of the students said they rarely or never socialized with their mentors, while the other half noted that they socialized with their mentors once or twice per term (Cronan-Hillix et al., 1986). If socializing can be used as a proxy measurement for friendship, half of the students surveyed were friends with their

\section{Table 1}

Terminology Used in Various Academic Publications to Describe Friendship and Similar Concepts Between Graduate Students and Faculty Advisors

\begin{tabular}{lll}
\hline Clutterbuck (2001) & Gardiner (2008) & Johnson (2008) \\
\hline Critical friend & Personal friendship & Collegiality \\
Close friend & Professional friendship & Mutuality \\
Mutual respect & Friendship relationship & Professional friendship \\
Friends in low places & Special form of friendship & \\
& & \\
Key friendship & Professional friend mentor & \\
& & \\
\end{tabular}


mentors, while the remaining half were not. In a similar study, Clark et al. (2000) surveyed 787 doctoral students in clinical psychology and found that on a scale of 1 (strongly disagree) to 5 (strongly agree), the mean score for "My mentor served as a friend" was $3.36(S D=1.23)$. This was the lowest rated function for all of Kram's (1988) nine functions. However, the mean score is above a neutral value of 2.50 , which suggests friendship was still present in a number of these mentoring relationships. When explaining their results, Clark et al. noted that the mentoring functions often associated with graduate education, such as direct training or instruction, support and acceptance, and role modelling, were the highest rated items. They suggested that these functions were consistent with roles often expected of faculty members, and functions such as friendship or protection, which are not as customary, were rated lower.

Young et al. (2004) discuss two case studies where faculty members and graduate students experienced "being simultaneously friends, mentors and mentees" (p. 23). This is an explicit acknowledgement of friendship occurring while still engaged in student and advisor roles. Studying their own experiences as three female doctoral students and two female professors, the group noted the interdependence of their relationships, which served to lessen some of the traditional mentor and protégé expectations; members were excited to learn from the others. Prior to recognizing these interdependences, one mentoring dyad wrote about how they intended to keep their friendship and mentoring relationships separate. Returning to their data after an absence of many years allowed them to see that they had analyzed only the professional aspects of their relationship, perhaps believing that there was an incompatibility when friendship was present in their mentoring relationship. It becomes clear that despite their initial intention to keep their personal and professional lives separate, these facets became intertwined as the individuals interacted with each other.

Despite the empirical evidence from Clark et al. (2000), Cronan-Hillix et al. (1986), Kram
(1988), Young et al. (2004), and our own previous work (Beres \& Dixon, 2014), it is not possible to pinpoint exactly when friendship develops in these mentoring relationships (assuming that it does indeed exist). Some students noted the simultaneous occurrence of friendship and mentoring (Clark et al., 2000; Young et al., 2004), while others described their current relationship with their former mentor as a friendship, but did not explicitly share when this process unfolded (Beres \& Dixon, 2014).

Kram's (1983, 1988) seminal study may offer some potential clues into this temporal development, but additional research is needed. Kram (1983) explained that most mentoring relationships pass through a predictable set of relationship phases. The first phase, initiation, lasts between six and twelve months and includes the start of the relationship. It is also when both parties replace any unrealistic fantasies with more concrete, realistic expectations. In the cultivation phase, which spans a period of two to five years, the mentor and protégé increase their interactions and their bond may deepen. The next six months to two years are marked by a period of separation, which generally includes a change in the physical or emotional structure of the relationship as the protégé becomes more autonomous. Finally, the mentor and protégé enter an indefinite period of time during which their relationship undergoes a redefinition. Although two-thirds of protégés in our study made explicit reference to a friendship component within their mentoring relationships, the retrospective nature of our study design means that most of the data were likely obtained while mentors and protégés were in the redefinition phase (Beres \& Dixon, 2014). Thus, definitive conclusions about when friendship emerges within these relationships remain elusive.

It is possible that, in some relationships, as the interactions and emotions increase throughout the cultivation phase (Kram, 1983), the mentor and protégé shift from a hierarchical relationship to something more like one between peers. It is also possible that a mentor and protégé would consider each other to have collegial but formal relations 
until the redefinition period. At this time, the relationship moves beyond an active mentoring relationship and both parties establish a friendlier, more personal relationship. We found evidence for this transition in our study, as one mentor specifically described the shift in her relationship, saying "we've moved away from the mentorprotégé relationship and we are friends." Like the mentors, a number of protégés also described how their relationships had evolved over time, noting, "I still look at [my advisor] as a mentor today, but I would say that, while I occasionally lean on her for mentoring, I think that the relationship has evolved to one of a collegial or friendship relationship as much as a mentoring relationship."

However, establishing that a friendship exists in the redefinition phase does not indicate whether the graduate students or their faculty advisors would have labelled their relationships as such prior to that transition. Given the many possible combinations of friendship development, and the unique nature of each individual relationship, it may be quite difficult to establish a uniform or consistent point at which friendship emerges. Regardless, additional research is required in order to provide greater understanding of the development of friendship in graduate studentfaculty advisor mentoring relationships.

\section{Conceptual Advancements}

At first glance, Gardiner's (1998, 2008) model of professional friendship may appear to offer a conceptual understanding of how the potentially incompatible roles of friendship and mentoring may co-exist. However, Gardiner's model does not depict what a successful professional friendship ought to include, nor does it explain how a professional friendship could develop with sufficient attention to both personal and professional aspects. Instead, Gardiner (1998) provides a listing of 26 features or processes that she suggests are integral to quality mentoring. Although features such as reliability, openness, honour, and empathy are highly valued, it is not clear how the successful application of these features "represents success in a friendship mentoring relationship" (Gardiner, 1998, p. 82).

Furthermore, a lack of operational definitions and discrepancies in original source materials cited by Gardiner (1998) prevent us from obtaining clarification on the topic of friendship in academic mentoring relationships. For example, she claims that "mentoring provides individuals with a relationship which builds from a foundation of friendship" (1998, p. 77). Unfortunately, she does not provide any empirical support for her claim, nor does she provide any discussion of how one would build this required friendship base if the 26 features were not present in a relationship. Of paramount concern, Gardiner does not define what she means by professional friendship, which makes it very difficult to understand the model and how it may apply to future analyses. For example, Gardiner lists "challenging" as a process involved in her model of professional friendship. We found evidence that the entire doctoral degree could be classified as a challenging assignment, and that within these programs, mentors set challenging expectations with regard to protégés' publishing outcomes (Beres \& Dixon, 2014). One mentor within our study even noted that her protégé once asked "whose side are you on?" and she replied, "I'm on your side but you know I have to push you a little bit too." Using Kram's (1988) functions as the framework for our analysis, we did not classify this aspect of their relationship as friendship, but rather under the career function of challenging assignments. The lack of detail in Gardiner's model prevents us from fully understanding "challenging," or many of the other elements of her model. Such definitional issues would need to be resolved before we could consider reclassifying our results using Gardiner's approach.

In her subsequent dissertation, Gardiner (2008) outlined her development of professional friendships and tested its utility in K-12 educational settings in the United Kingdom. Using a mixed-method approach, she sought to understand the extent to which professional friendship is a core component of mentoring and how her model of professional friendship could be 
improved. She claims that most learning mentors acted as professional friends and that her model helped to identify successful mentoring relationships. Based on the results of her evaluation, she was able to make improvements to her model, which included updating aspects of the 26 features of professional friendship advanced earlier (Gardiner, 1998).

Although Gardiner's (2008) study was conducted in an educational setting, contextual factors may reduce the transferability of her findings. She studied learning mentors, who are educational practitioners assigned to support underserviced, inner-city primary school children and their families. Based on Gardiner's description, learning mentors strive to increase social cohesion, self-esteem, and learning opportunities inside and outside of schools, while decreasing bullying, truancy, and disruptive behaviour. Given possible differences in the mentoring actions of learning mentors and graduate-level faculty advisors, applying Gardiner's findings to graduate studentfaculty advisor mentoring relationships may be inappropriate. While the idea of developing a model of professional friendship is noteworthy and could address a significant gap in the literature, further study and refinement must be undertaken before Gardiner's (1998, 2008) model of professional friendship can be applied to graduate student-faculty advisor mentoring relationships.

\section{Possible Incompatibility of Friendship and Mentoring}

In contrast to the support for friendship in graduate student-faculty advisor mentoring relationships demonstrated by the aforementioned empirical and conceptual publications, Johnson (2008; Johnson \& Huwe, 2003) has concerns about the possible incompatibility of roles when students and advisors develop friendship-like relationships. He notes that as the relationships between graduate students and faculty members deepen, faculty mentors become "increasingly partisan advocates" (2008, p. 31) for their students, which may impede the mentors' abilities to provide objective evaluations of students' strengths and weaknesses. This is especially problematic when faculty mentors are responsible for determining students' competence to practice in professional fields including medicine, clinical psychology, engineering, or law, among others. We searched our data but unfortunately were unable to find any support that matched Johnson's concerns noted here (or in the paragraph below). Given the contextual aspects of our study (faculty members within sport management), this is perhaps not surprising. We wonder what we might find if we were to speak with faculty in the abovementioned professional fields. Perhaps faculty in these areas would express concerns about the incompatibility of friendship and mentoring. Regardless, the notion of role incompatibility offers many potential directions for future study.

Johnson (2008) asserts that few scholars have addressed the possible negative consequences that may arise when students and advisors engage in friendship or similar interpersonal functions, such as advocacy and mutuality. He offers suggestions to reduce the strain and negative outcomes that stem from these incompatible roles. For example, he reminds faculty members of their ethical imperative to remain as gatekeepers of their professions. He cites empirical evidence for a strong correlation between disciplinary action by medical boards and documented cases of unprofessional behaviour during medical school. Given their roles in evaluating performance and determining competence, faculty advisors must remain objective. While not explicitly stated, the implication is that friendship and mentoring should not mix. This contrasts with the positive inferences about friendship revealed by Young et al. (2004) and within our own previous research (Beres \& Dixon, 2014). As described above, we were unable to find data within our study that would provide adequate support for the idea of gatekeeping.

A number of other authors make more implicit claims about the possible incompatibility of friendship and mentoring. By subtly shifting 
from using the words "friendship" and "friend" to terms such as "mutuality," "collegiality," and other related terms found in the literature, or adding a qualifying word like "professional" to the description of friendship (Gardiner, 2008; Johnson, 2008), the implication is that the relational experiences found in academic mentorships are not the same as friendship between two individuals connected through a nonmentoring relationship.

\section{A Call for Future Research}

As we have noted above, there is support for the presence of friendship in graduate student-faculty advisor mentoring relationships. However, this support is varied, and clarification cannot be found in the existing literature. At present, issues of semantics and conceptual differences, perceived incompatibilities, and contextual differences remain unresolved. We recommend that additional research be conducted on the aforementioned aspects of friendship in academic mentoring relationships, and specifically graduate studentfaculty advisor relationships, with the hope of strengthening these important interpersonal interactions.

\section{Exploring Semantics and Conceptual Differences}

One challenge in conducting research on the topic of mentoring is that individuals must describe their relationships using a common language. However, specific terms may have different meanings for different individuals. For example, the very notion of friendship may vary from one individual to the next. What one person expects from a friend may differ dramatically from what another individual would consider to be friendship. Furthermore, it is possible that people may use the same term (e.g., friendship) to describe a wide variety of relationships in their own lives. Personal and cultural values or academic disciplinary differences may further complicate individuals' use of similar terms. Although adjectives such as "professional" or "personal" may be added to provide additional description, individuals may still be categorizing many different types of interpersonal relationships with the same term. It is possible that the English language does not contain a word that adequately captures the nuances of mentoring relationships involving graduate students and their faculty advisors, while still differentiating from similar yet distinct relationships that may occur in their personal lives or in other contexts. Perhaps friendship is the closest English word, and thus, is the term that individuals use when trying to communicate the complexities of these relationships.

In addition, because authors have often failed to provide operational definitions of friendship, participants are left to interpret what is meant by friendship and how this may (or may not) apply in their own mentoring relationships. This lack of clarity means the literature on friendship continues to be poorly defined, and becomes increasingly difficult to interpret. It also means that it may not be possible to clearly determine whether scholars are trying to disentangle conceptually distinct aspects of mentoring, or whether individuals are struggling with personal semantic interpretations.

One example of this potential confusion can be found in a summary of a panel presentation on mentoring minority doctoral students (Lederman, 2008). Two panelists appeared to support the fundamental idea that mentoring relationships should involve more than simply providing career guidance, and should include elements of a personal relationship. One panelist described his recent realization that "friendship is an essential component of being a true mentor" (para. 2). In response, another panelist noted that it was essential to have an "emotional connection" and "a level of caring" (para. 3) in a mentoring relationship, "but that friendship is not the correct term" (para. 3) to describe this interpersonal relationship. Further discussion on the topic revealed individual differences in the meaning of 
friendship; the individual who insisted that friendship should be present in mentoring relationships disclosed that he did not envision having the sort of "personal entanglements" (para. 11) that others were alluding to in their descriptions of friendship.

Much like the stories shared in Lederman's (2008) article, one mentor from our study expressed potentially contradictory remarks about his involvement with students' personal lives. Although he explicitly called his former doctoral students his "life friends," he also suggested that he intentionally distances himself from aspects of their personal lives while actively serving as their dissertation advisor. Based on the exchange in the aforementioned panel presentation and some of the findings from our study, it is not clear whether individuals are struggling with different interpretations of the same concept, or whether there are significant conceptual differences in understanding the role of friendship in graduate student-faculty advisor mentoring relationships. Consequently, we recommend that individuals conducting research in the area of mentoring provide greater clarification regarding their conceptualization of the friendship function. We recognize that scholars may want to avoid providing an exacting definition of friendship so they may gather participants' own descriptions. In these cases, we ask that scholars explicitly note this methodological choice, and we recommend that participants be asked to describe friendship from their own perspectives, with scholars subsequently sharing these descriptions with their audiences.

\section{Confirming Perceived Incompatibilities}

As previously noted, Johnson (2008; Johnson \& Huwe, 2003) has expressed concerns about the possible incompatibility of friendship in graduate student-faculty advisor mentoring relationships. This possible incompatibility represents a potentially significant risk or disadvantage of developing friendship in mentoring relationships, which has otherwise been generally described as a positive feature of mentoring relationships. Therefore, we recommend that future research empirically test whether graduate students, faculty advisors, and others, such as those serving on professional regulatory bodies, perceive friendship in mentoring relationships to be incompatible. Incorporating Kram's (1983) redefinition phase suggests that friendship may not develop until the active mentoring phases of the relationship have been completed. In this case, mentors may be able to offer non-partisan and objective evaluations of their protégés' competence and then transition into more collegial interactions. Conducting a comparative study of students' licensing exam scores as completed by mentors and non-mentors may offer insight into whether friendship and mentoring are incompatible. If mentors' judgements are found to be biased, one potential solution may be to require that critical competency evaluations be conducted by neutral, objective individuals. This would allow graduate students and faculty advisors to develop and benefit from interpersonal relationships without risking public safety.

\section{Examining Contextual Differences}

In contrast to the aforementioned suggestion that friendship may form during a certain point in time, it is also possible that friendship does not form in a predictable or constant phase of the mentoring relationship. Each mentoring relationship is unique and individual differences may influence friendship development. For example, graduate students' and faculty advisors' personal values and cultural beliefs will figure prominently in individual interpersonal relationships. Similarly, accepted differences in academic disciplines, such as the nature of the work undertaken in the mentoring relationships or the length of time to degree completion (Lovitts, 2001) may influence the mentoring relationships in such detail that it may not be possible to develop a universal representation of friendship in graduate student-faculty advisor mentoring relationships. Other relationships may be affected when graduate 
students express a desire to change their current academic paths or future career trajectories, with a resulting impact on the development, or lack thereof, of friendship. For example, if students wish to pursue a career outside of academia, the current relationship between graduate students and faculty advisors may be impacted-either positively or negatively-and this may, in turn, strengthen or impede elements of friendship. We recommend conducting longitudinal studies using matched pairs of graduate students and faculty advisors, as this would allow for real-time evaluation of when, if at all, friendship developed and specifically how it affects academic outcomes. As McCarron (2006) has noted, despite Kram's (1988) exploration of both mentors' and protégés' perspectives, many studies (e.g., Clark et al., 2000; Cronan-Hillix et al., 1986; Schlosser \& Gelso, 2001; Tenenbaum et al., 2001) on mentoring relationships are routinely conducted by examining the perspectives of only one member (i.e., mentors or protégés). By conducting studies with matched mentor-protégé pairs, researchers could also compare perceptions of both members, further adding to the knowledge base about graduate student-faculty advisor mentoring relationships.

\section{Conclusions}

Previous research has shown that friendship can develop within mentoring relationships (Kram, 1988). As demonstrated above, two quantitative studies (Clark et al., 2000; Cronan-Hillix et al., 1986) and two qualitative studies (Beres \& Dixon, 2014; Young et al., 2004) provide support for the presence of friendship relationships between graduate students and their faculty advisors. However, having a friendship relationship during the redefinition phase of a mentoring relationship does not mean that friendship was present during any of the three previous phases (Kram, 1983). These insights, and the lack of clarity in the existing literature, provide support for future studies that examine what role, if any, friendship plays in academic mentoring relationships between graduate students and their faculty advisors.

The insights gleaned from this paper could be useful for a number of individuals. For example, faculty members who are engaged in mentoring relationships can reflect upon the possible role of friendship in their own relationships, and decide what, if any, future actions they may wish to pursue in order to develop possible friendship relationships. Educational developers, who support faculty members and graduate students, may also be interested in these findings as the information could be shared through professional development workshops. In addition, current and prospective graduate students can benefit from this discussion of friendship, especially if they are mentored-or wish to be mentored-by a faculty advisor throughout their graduate education. Finally, if the research areas discussed above are addressed through empirical studies, it might be possible that the lack of consensus about friendship in graduate student-faculty advisor mentoring relationships could be ameliorated, and in time, academic mentoring relationships could be strengthened.

\section{References}

Allen, T. D., Eby, L. T., Poteet, M. L., Lentz, E., \& Lima, L. (2004). Career benefits associated with mentoring for protégés: A meta-analysis. Journal of Applied Psychology, 89, 127-136. https://dx.doi. org/10.1037/0021-9010.89.1.127 VIEW ITEM

Bearman, S., Blake-Beard, S., Hunt, L., \& Crosby, F. J. (2010). New directions in mentoring. In T. D. Allen, \& L. T. Eby (Eds.), The Blackwell handbook of mentoring: $A$ multiple perspectives approach (pp. 375395). Chichester, UK: Wiley-Blackwell.

Beres, J. L., \& Dixon, J. C. (2014). Exploring mentoring functions within the sport 
management academy: Perspectives of mentors and protégés. Sport Management Education Journal, 8, 14-26. http://dx. doi.org/10.1123/SMEJ.2012-0007 VIEW ITEM

Bozeman, B., \& Feeney, M. K. (2007). Toward a useful theory of mentoring: A conceptual analysis and critique. Administration \& Society, 39, 719-739. https://dx.doi.org $/ 10.1177 / 0095399707304119 \quad$ VIEW ITEM

Ciuffetelli Parker, D., \& McQuirter Scott, R. (2010). From mentorship to tenureship: A storied inquiry of two academic careers in education. Mentoring \& Tutoring: Partnership in Learning, 18, 405-425. https://dx.doi.org/10.1080/13611267.20

10.511849 VIEW ITEM

Clark, R. A., Harden, S. L., \& Johnson, W. B. (2000). Mentor relationships in clinical psychology doctoral training: Results of a national survey. Teaching of Psychology, 27, 262-268. https://dx.doi.org/10.1207/S15 328023TOP2704_04 VIEW ITEM

Clutterbuck, D. (2001). Everyone needs a mentor: Fostering talent at work ( $3^{\text {rd }}$ ed.). London, UK: Chartered Institute of Personnel and Development.

Cronan-Hillix, T., Gensheimer, L. K., CronanHillix, W. A., \& Davidson, W. S. (1986). Students' views of mentors in psychology graduate training. Teaching of Psychology, 13, 123-127. https://dx.doi.org/10.1207 /s15328023top1303_5 VIEW ITEM

De Four-Babb, J., Pegg, J., \& Beck, M. (2015). Reducing intellectual poverty of outsiders within academic spaces through informal peer mentoring. Mentoring \& Tutoring: Partnerships in Learning, 23, 76-93. https://dx.doi.org/10.1080/13611267.20 15.1011038 VIEW ITEM

Dorsey, L. E., \& Baker, C. M. (2004). Mentoring undergraduate nursing students: Assessing the state of science. Nurse Educator, 29, 260-265.

Eby, L. T., Allen, T. D., Evans, S. C., Ng, T., \& DuBois, D. L. (2008). Does mentoring matter? A multidisciplinary meta-analysis comparing mentored and non-mentored individuals. Journal of Vocational Behavior, 72, 254-267. https://dx.doi.org/10.1016/ j.jvb.2007.04.005 VIEW ITEM

Gardiner, C. (1998). Mentoring: Towards a professional friendship. Mentoring \& Tutoring: Partnership in Learning, 6, 7784. https://dx.doi.org/10.1080/0968465 980060107 VIEW ITEM

Gardiner, C. E. (2008). Mentoring: Towards an improved professional friendship (Doctoral dissertation). Retrieved from http://etheses.bham.ac.uk/187/ VIEW ITEM

Golde, C. M. (2005). The role of the department and discipline in doctoral student attrition: Lessons from four departments. Journal of Higher Education, 76, 669-700. Retrieved from http://www.jstor.org/stable/383 8782 VIEW ITEM

Griffin, S. M., \& Beatty, R. J. (2012). Hitting the trail running: Roadmaps and reflections on informal faculty mentorship experiences. In M. S. Barrett \& S. L. Stauffer (Eds.), Narrative surroundings: An anthology of narrative inquiry in music education (pp. 251-273). Dordrecht, Netherlands: Springer Science + Business Media. https://dx.doi.org/10.1007/978-94-0070699-6_14 VIEW ITEM 
Johnson, W. B. (2008). Are advocacy, mutuality, and evaluation incompatible mentoring functions? Mentoring \& Tutoring: Partnership in Learning, 16, 31-44. https://dx.doi.org/10.1080/13611260701 800942 VIEW ITEM

Johnson, W. B., \& Huwe, J. M. (2003). Getting mentored in graduate school. Washington, DC: American Psychological Association.

Kanter, R. M. (1977). Men and women of the corporation. New York, NY: Basic Books.

Kram, K. E. (1983). Phases of the mentor relationship. Academy of Management Journal, 26, 608-625. Retrieved from http://www.jstor.org/stable/255910 VIEW ITEM

Kram, K. E. (1988). Mentoring at work: Developmental relationships in organizational life. Boston, MA: University Press of America.

Lederman, D. (2008, October 28). Mentor, friend - or both? Inside Higher Education. Retrieved from https://www.insidehigher ed.com/news/2008/10/28/mentor VIEW ITEM

Lovitts, B. E. (2001). Leaving the ivory tower: The causes and consequences of departure from doctoral study. Lanham, MD: Rowman \& Littlefield.

McCarron, M. C. E. (2006). The experiences of mentoring and being mentored in academia: Perspectives of mentors and protégées (Master's thesis). Available from ProQuest Dissertations and Theses database. (UMI No. MR18902)

Paglis, L. L., Green, S. G., \& Bauer, T. N. (2006). Does adviser mentoring add value? A longitudinal study of mentoring and doctoral student outcomes. Research in Higher Education, 47, 451-476. https://dx.doi.org/10.1007/s11162-005-

9003-2 VIEW ITEM

Savin-Baden, M., \& Major, C. H. (2013). Qualitative research: The essential guide to theory and practice. New York, NY: Routledge.

Schlosser, L. Z., \& Gelso, C. J. (2001). Measuring the working alliance in advisor-advisee relationships in graduate school. Journal of Counseling Psychology, 48(2), 157-167. https://dx.doi.org/10.1037/0022-0167.48 .2 .157 VIEW ITEM

Strauss, A., \& Corbin, J. (1998). Basics of qualitative research: Techniques and procedures for developing grounded theory ( $2^{\text {nd }}$ ed.). Thousand Oaks, CA: Sage.

Tenenbaum, H. R., Crosby, F. J., \& Gliner, M. D. (2001). Mentoring relationships in graduate school. Journal of Vocational Behavior, 59, 326-341. https://dx. doi.org/10.1006/jvbe.2001.1804 VIEW ITEM

Wrightsman, L. S. (1981, August). Research methodologies for assessing mentoring. Presented at the Annual Conference of the American Psychological Association, Los Angeles, CA. (ERIC Document Reproduction Service No. ED 209 339).

Yin, R. K. (2009). Case study research: Design and method ( $4^{\text {th }}$ ed.). Thousand Oaks, CA: Sage.

Young, J. P., Alvermann, D., Kaste, J., Henderson, S., \& Many, J. (2004). Being a friend and a mentor at the same time: A pooled case comparison. Mentoring \& Tutoring: Partnership in Learning, 12, 23-36. 
https://dx.doi.org/10.1080/13611260420

00183066 VIEW ITEM

\section{Biographies}

Jacqueline Beres is a $\mathrm{PhD}$ student in Social, Cultural, and Political Contexts of Education at Brock University, with a focus on higher education. Her interests include mentoring and socialization, the Scholarship of Teaching and Learning (SoTL), and research methodologies.

Jess Dixon is an Associate Professor in the Department of Kinesiology at the University of Windsor, and is associate editor of Case Studies in Sport Management, a peer-reviewed journal dedicated to publishing teaching cases in the field of sport management. His interests include case pedagogy, student mentoring, and peer observation. 